\title{
Time-dependency of the ${ }^{137} \mathrm{Cs}$ activity concentration in freshwater lakes, measurement and prediction
}

\author{
G. Zibold, S. Kaminski, E. Klemt and J.T. Smith' \\ Fachhochschule Ravensburg-Weingarten University of Applied Sciences, \\ 88250 Weingarten, Germany \\ ' Centre for Ecology and Hydrology, Winfrith Technology Centre, Dorchester, Dorset, U.K.
}

\begin{abstract}
Chernobyl, activity concentrations of lake water are measured as $0.06 \mathrm{mBq} / 2 \mathrm{mBq} /$ : and $60 \mathrm{mBq} /$ in Lake Consance, Lake Lugano and Lake Vorsee. These values can be explained by differences in limnological character of these lakes. To describe and predict the data of lake water contamingtion we use (1) a simple exponential "transfer function" model for the runoff of activity from contaminated catchments, and assume that runoff water determines lake water contamination. In a second approach (2) lake water residence times and ${ }^{131} \mathrm{Cs}$ uptake by sediments are taken into account together with runoff. With their blind predictions both models describe the ${ }^{[37} \mathrm{Cs}$ contamination in lake water of the three lakes quite well. Based on the second approach, a fish model is used to blindly predict the fish contamination in Lake Constance and Lake Vorsee with a deviation smaller than factor 10 from measured values. Attempts to use these models also for a number of other lakes in Europe and in the CIS countries near to the site of Chemobyl are promising with respect to a generalisation of our results to predict ${ }^{137} \mathrm{Cs}$ contamination of freshwater lakes for radiation protection parposes in case of emergency.
\end{abstract}

\section{INTRODUCTION}

Following a fallout event, radionuclides are removed from a lake through the outflow and to bottom sediments. Transfers to bottom sediments ocaur as a result of attachment to and settling of suspended particles and via direct diffusion across the sediment/water interface. In the longer term, radionuclides like ${ }^{37} \mathrm{Cs}$ may potentially be remobilised from bottom sediments, under anoxic conditions, or resuspended by biological and physical turbation. In addition to these mechanisms, tributaries transport radionuclides from the contaminated catchment in the lake. In the runoff model this transport out of the catchment is considered only.

\section{RESULTS AND DISCUSSION}

\subsection{Runoff model}

In this model [1-3] is assumed, that the activity concentrations of lake water and of water flowing in the lake from the catchment are the same. For this study we will use an exponential "transfer function" model $[4$, I] for the runoff of activity from contaminated catchments as described by Monte 1995 and Smith et al. 1999. This model assumes three components to the transfer.

- a short term (timescale, $\tau \sim 30 \mathrm{~d}$ ) transfer of recently deposited activity,

- a medium term exponential decline ( $\tau \sim$ years) as a result of changing availability of the radionuclide in catchment soils and

- a long-term ( $\tau \sim$ decades) "equilibrium" value.

$C_{R}\left(\right.$ Bq. $\left.\mathrm{m}^{-3}\right)$, the radionuclide concentration in runoff water is given by: 
$C_{R}(t)=D\left(\alpha e^{-\left(\lambda+k_{1}\right) t}+\beta e^{-\left(\lambda+k_{2}\right) t}+\gamma e^{-\left(\lambda+k_{3}\right) t}\right)$

where $\lambda$ is the decay constant of the radionuclide and $D$ is the radionuclide fallout $\left(\mathrm{Bq} \cdot \mathrm{m}^{-2}\right)$ on the catchment. $\alpha, \beta, \gamma\left(\mathrm{m}^{-1}\right)$ and $k_{1}, k_{2} k_{3}\left(\mathrm{y}^{-1}\right)$ are empirically determined constants

From extensive data sets of ${ }^{137} \mathrm{Cs}$ in runoff water the following parameter values resulted [2]:

$$
\begin{aligned}
& \alpha=0.3 m^{-1} \\
& k_{I}=18 y^{1} \\
& \beta=0.003\left(f_{\min }\right)+0.05\left(f_{\text {arg }}\right) \quad m^{-1} \quad k_{2}=0.41 y^{-1} \\
& \gamma=0.0002\left(f_{\operatorname{man}}\right)+0.007\left(f_{\text {org }}\right) m^{-1} \quad k_{3}=0.02 y^{-1}
\end{aligned}
$$

Where $f_{\text {org }}$ is the fractional coverage of the catchment by organic, boggy soils and $f_{\min }\left(=1-f_{\text {org }}\right)$, the fractional coverage by non-organic soils. This set of parameter values is used in the following models to make blind predictions for the ${ }^{137} \mathrm{Cs}$ activity concentration in water and fish of three different lakes. Required input data for the "Runoff-model" is the deposition, $\mathrm{D}$, and the catchment coverage by organic, boggy soils, forg.

In Fig. 1 the result of the runoff model is given for Lake Constance, Lake Vorsee and Lake Lugano. The following input data have been used:

Table 1 : Input data of the nunoff model for lake water from catchments having fractional coverage by organic soils $f_{o r}$ and ${ }^{137} \mathrm{Cs}$ inventory $D$ and decay constant $\lambda$.

\begin{tabular}{|l|c|c|c|}
\hline Lake & $\boldsymbol{f}_{\boldsymbol{t}}$ & $\left.\boldsymbol{D} \mathbf{\mathrm { kBq }} / \mathbf{m}^{2}\right]$ & $\boldsymbol{\lambda}\left[\mathbf{\mathbf { a }}^{-1}\right]$ \\
\hline Constance & 0 & $\mathbf{7 , 6}$ & $\mathbf{0 , 0 2 2 9 5}$ \\
\hline Vorseo & 0,2 & $\mathbf{2 8}$ & 0,02295 \\
\hline Lugano & 0 & $\mathbf{2 4}$ & $\mathbf{0 , 0 2 2 9 5}$ \\
\hline
\end{tabular}

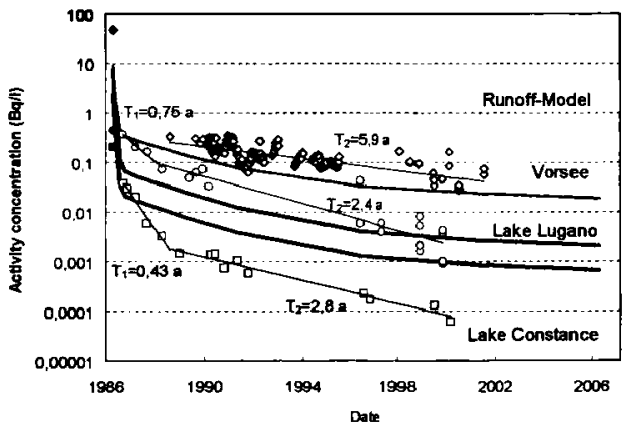

Figore 1: Time-dependency of ${ }^{137} \mathrm{Cs}$ activity concentration of water in three prealpine lakes. measured data with trend lines and ecological half-lives $T_{1}$ and $T_{2}$. Runoff model calculated until 2006. Full symbols give initial values. 
In Fig. 1 data measured [5-8], are presented together with trend lines for these data points. For the year 2000 a good fit of the data is achieved for lakes Vorsee and Lugano. For Lake Lugano activity concentrations given at the same sampling date are for different water depth, and they increase in value with water depth. For Lake Constance measured values are a factor 10 smaller than fitted values. It is known $[9,10]$ that the catchment of Lake Constance is rich in clay minerals, e.g. illite, which can fix ${ }^{137} \mathrm{Cs}$, so that activity concentration of nunoff water is smaller for this catchment as compared to the catchments of the other two lakes. The initial decline in contamination in lakes is determined not by runoff but by in-lake processes, thus $\ln 2 / \mathrm{k}_{1}$ is different from the experimental $T_{1}$, which is the lake Cs residence time.

\subsection{Lake model}

This model [1-3] takes into account nunoff from the catchment, outflow and sedimentation of suspended particulates. By consideration of mass balance, we can write a differential equation for $C_{L}\left(\mathrm{~Bq} \cdot \mathrm{m}^{-3}\right)$, the total lakewater concentration of the radionuclide, dissolved in the water and adsorbed to suspended particulates:

$$
\frac{d C_{L}}{d t}=\frac{C_{R}}{\tau_{w}}-\frac{C_{L}}{\tau_{w}}-\frac{C_{L}}{\tau_{L}}-\lambda C_{L}
$$

$C_{R}\left(\mathrm{~Bq} \cdot \mathrm{m}^{-3}\right)$ is the activity concentration of inflowing streams as estimated by Equation (1). $\tau_{\mathrm{w}}$ the water residence time constant is defined under the assumption that discharges of water through the outflow and inflow are about the same. $\tau_{1}$, the residence time constant for uptake by sediments represents transport to the sediments via attachment to and settling of suspended particulates, diffusion is not considered. $\lambda\left(y^{-1}\right)$ is the radioactive decay constant.

The model for prediction of ${ }^{137} \mathrm{Cs}$ in lake water is [1-3]

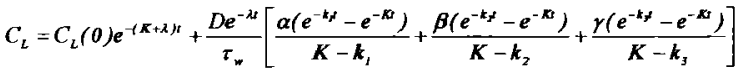

$C_{L}(0)\left(\mathrm{Bq} \cdot \mathrm{m}^{-3}\right)$ is the initial mean lakewater concentration (shown in Fig. 1 and Fig. 2 as open symbols). $\alpha$, $\beta, \gamma, k_{l}, k_{2}, k_{y}$ are the same parameters and have the same values as in the nunoff model above. $D$ is the deposition to the catchment, also as in the runoff model above. $K, C_{L}(0)$ and $\tau_{\mathrm{L}}$ are given by:

$$
K=I / \tau_{w}+l / \tau_{L} \quad C_{L}(0)=\frac{D_{L}}{\delta} \quad \tau_{L} \approx \delta / f_{p} v_{p}
$$

where $D_{L}\left(\mathrm{~Bq} \cdot \mathrm{m}^{-2}\right)$ is the deposition per square metre of lake surface, $\delta(\mathrm{m})$ is the mean depth of the lake, $v_{p}\left(\mathrm{~m} \cdot \mathrm{y}^{-1}\right)$ is the particulate settling velocity, $f_{p}$ is the dimensionless fraction of activity sorbed to suspended particles, determined by $K_{d}\left(\mathrm{~m}^{3} \cdot \mathrm{kg}^{-1}\right)$, the solids-aqueous distribution coefficient, and $s\left(\mathrm{kgm}^{-3}\right)$ the suspended solids concentration as

$$
f_{p}=\frac{s K_{d}}{I+s K_{d}} .
$$

Measured data and input values to the model are collected in table 2

In Fig. 2 the result of the lake model calculation is presented together with measured values. Especially for Lakes Constance and Lugano, agreement between measurement and modelling is satisfying . For Lake Vorsee calculated activity concentrations are too small by factor 3 . The values of $K_{d}$ in table 2 are measured with respect to the exchangeable ${ }^{137} \mathrm{Cs}[11,12]$. For the chosen values of parameters the lake 
model underestimates the contamination. For Lake Vorsee a reported seasonal redissolution of ${ }^{137} \mathrm{Cs}$ from the sediment [13], not considered in the model, could add to this underestimation. It is known that ${ }^{137} \mathrm{Cs}$ is bound tightly in the sediment of Lake Constance [10], whereas less tightly in that of Lake Lugano [14]

Table 2: Characteristics of lakes studied

\begin{tabular}{|l|c|c|c|}
\hline Properties & $\begin{array}{c}\text { Lake } \\
\text { Constance }\end{array}$ & $\begin{array}{c}\text { Lake } \\
\text { Vorsee }\end{array}$ & $\begin{array}{c}\text { Lake } \\
\text { Lugano }\end{array}$ \\
\hline Lake surface $\left(\mathrm{km}^{2}\right)$ & 572 & 0,09 & $48,9($ total $)$ \\
\hline Max. water depth $(\mathbf{m})$ & 254 & 2,2 & 288 \\
\hline Catchment area $\mathrm{A}_{6}\left(\mathbf{m}^{2}\right)$ & $11487 \mathrm{E}+06$ & $1,27 \mathrm{E}+06$ & $615 \mathrm{E}+06$ \\
\hline Potassium concentration $\left[\mathrm{K}^{\prime}\right]\left(10^{-6} \mathrm{Eq} / \mathrm{A}\right)$ & 25 & 50 & 10 \\
\hline
\end{tabular}

\begin{tabular}{|l|c|c|c|}
\hline Values used in the model & $\begin{array}{c}\text { Lake } \\
\text { Constance }\end{array}$ & $\begin{array}{c}\text { Lake } \\
\text { Vorsee }\end{array}$ & $\begin{array}{c}\text { L. Lugano } \\
\text { South. Bas. }\end{array}$ \\
\hline Mean water depth $\delta(\mathbf{m})$ & 85 & 0,6 & 55 \\
\hline Time constant $\tau_{w}(\mathbf{a})$ & $\mathbf{4 , 1}$ & 0,24 & 2,5 \\
\hline Deposition on lake surface $D_{l}\left(\mathrm{kBg} / \mathrm{m}^{2}\right)$ & 17 & 28 & 24 \\
\hline Suspended solids concentration $s\left(\mathrm{~kg}^{-3} \mathbf{m}^{-3}\right)$ & 0,001 & 0,005 & 0,0007 \\
\hline Particulate settling velocity $v_{p}\left(\mathrm{~m} \mathrm{a}^{-1}\right)$ & 2370 & 401 & 401 \\
\hline Distribution coefficient $K_{d}\left(\mathrm{~m}^{3} \mathrm{~kg}^{-1}\right)$ & 33 & 1 & 5 \\
\hline Fraction of activity sorbed to particles $f_{p}$ & 0,032 & 0,005 & 0,0035 \\
\hline Rate $K\left(\mathrm{a}^{-1}\right)$ & 1,14 & 7,5 & 4,25 \\
\hline Initial activity concentration $C_{L}(0)\left(\mathrm{Bq} / \mathrm{m}^{3}\right)$ & 200 & 46667 & 400 \\
\hline
\end{tabular}

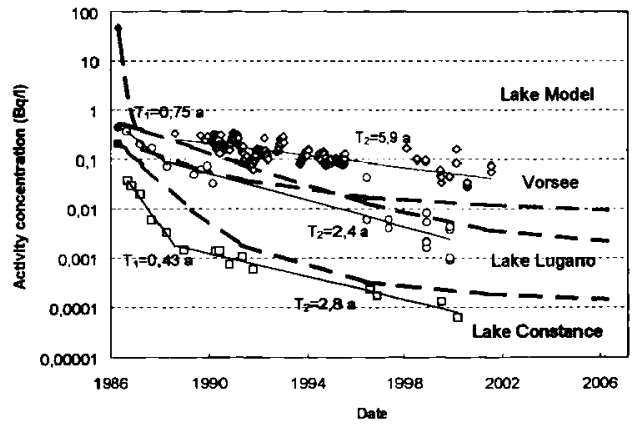

Figure 2: Time-dependency of ${ }^{137} \mathrm{Cs}$ activity concentration of water in three prealpine lakes, measured data with trend lines and ecological half-lives $T_{1}$ and $T_{2}$. Lake model (dushed) calculated unil 2006. Full symbols give initial values.

\subsection{Comparison of ecological half-lives of European lakes}

Smith et al. $[2,3]$ compared the time-dependency of the ${ }^{137} \mathrm{Cs}$ activity concentration in water of several European lakes. In Fig. 3 some of their data and the results for the three lakes of this study are given for the ecological half-lives $T_{1}$ and $T_{2}$ for 17 and 20 lakes respectively. Fig. 3 indicates that ecological half- 
lives of lakes are distributed log-normally and geometric mean values are $T_{1 \mathrm{gm}}=0,41$ years and $T_{2 \mathrm{gm}}=$ 2,7 years. Deviations from the log-nomal distribution for small $T_{1}$ are probably due to overlap with ecological half-times belonging to a time window of even smaller values. These values are not included in the geometric mean values given in Fig.3.

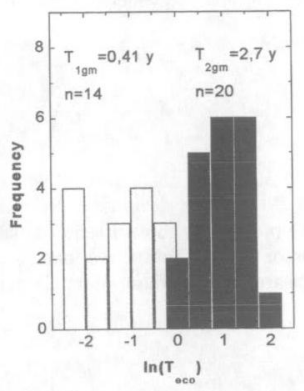

Tigare 3: Frequency distribution of the logarithm of ecological half-lives $T_{\infty \infty 0}$ and geometric mean values $T_{10 m}$ and $T_{2 m}$ of the ${ }^{137} \mathrm{Cs}$ activity concentration in European lakes [1-7].

\subsection{Fish contamination in Lake Constance and Lake Vorsee}

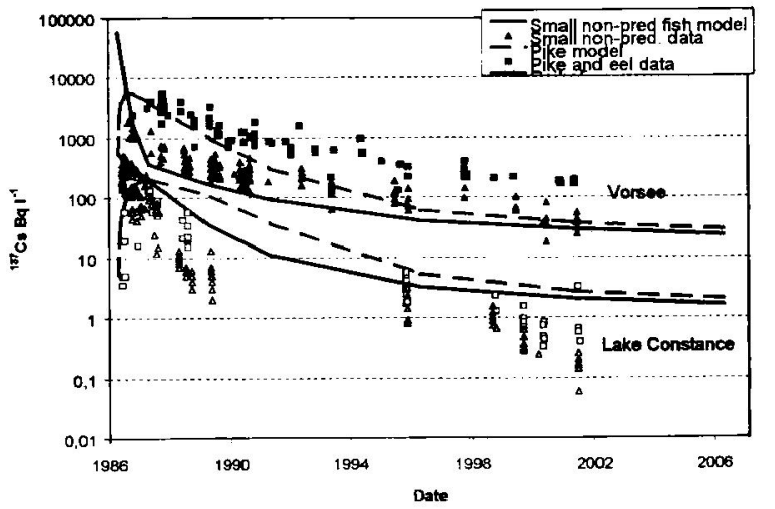

Figure 4: Time-dependency of ${ }^{137} \mathrm{Cs}$ activity concentration of fish in 2 pre-alpinc lakes. measured data and fish model blind predection until 2006. 
On the basis of the "lake model", Smith et al. [15] proposed a "fish" model which takes into account that the fish-water concentration factor of ${ }^{137} \mathrm{Cs}$ is inversely proportional to potassium concentration as the uptake rate of ${ }^{137} \mathrm{Cs}$ in fish is negatively correlated with lake potassium concentration. We used values for potassium and other parameters as given in table 1 and our data $[8,10]$ for a blind prediction of fish contamination in Lake Constance and Vorsee shown in Figure 4. Again, as in the case of lake water, the model underestimates the contamination of fish in Lake Vorsee and overestimates that in Lake Constance. However, deviations are smaller than a factor 10 , and the general trend of our measurements is well reproduced by the model.

\section{SUMMARY}

Simple models allow to blindly predict the ${ }^{137} \mathrm{Cs}$ activity concentration of water and fish of different lakes as a function of time for about 15 years since 1986 with a deviation from measured values smaller than factor 10. Results of these models are useful to predict the contamination of lake water and fish for other lakes, and for the calculation of the distribution of ${ }^{137} \mathrm{Cs}$ in bottom sediments [13]. Ecological half-lives of ${ }^{137} \mathrm{Cs}$ in lake water of about 20 European Lakes are distributed log-normally in several time windows.

\section{References}

[1] J.T. Smith, D.R.P. Leonard, J. Hilton, and P.G. Appleby, Health Phys. 72, 880-892 (1997)

[2] J.T. Smith, S.V. Fesenko, B. J. Howard, A.D. Horrill, N.I. Sanzharova, R.M. Alexakhin, D.G. Elder and C. Naylor, Environ. Sci. Technol 33, $49-54$ (1999)

[3] J.T. Smith, R.N J Comans and D.G. Elder, Water Research 33, 3762-3774 (1999).

[4] L. Monte, J. Environ. Radioactivity 26, 71-82 (1995).

[5] A. Mangini, U. Christian, M. Barth, W. Schmitz and H.H. Stabel, in Large Lakes, Ecological Structure and Function, edited by M.M. Tilzer and C. Serruya, (Springer Verlag, Berlin, 1990) pp. 245-264.

[6] P.H. Santschi, S. Bollhalder, S. Zingg, A. Lück and A. Farrenkothen, Environ. Sci. Technol 24, 4, $71-82(1990)$.

[7] J. Dominik and D. Span, Aquatic Sciences 54, 3/4, 238-255 (1992).

[8] E. Klemt, J. Drissner, S. Kaminski, R. Miller and G. Zibold, in: Contaminated Forests, edited by I. Linkov and W.R. Schell (Kluwer Academic Publishers, Netherlands 1999), pp. 95-101.

[9] J.A. Robbins, G. Lindner, W. Pfeiffer, J. Kleiner, H.H. Stabel and P. Frenzel, Geochim. Cosmochim. Acta 56, 2339-2361 (1992).

[10] S. Kaminski, A. Konoplev, G. Lindner and HG Schröder, Arch. Hydrobiol. Spec. Issues Advanc. Limnol. 53 - Lake Constance, Characterization of an ecosystem in transition, 365-405 (1998).

[11] E. Klemt, G. Zibold, M. Burger, E. Schmid, A. Barbieri und M. Simona, in Umweltradioaktivität und Strahlendosen in der Schweiz, (Bundesamt für Gesundheit, Schweiz, Bern, 2001) to be published.

[12] A. Konoplev, S. Kaminski, E. Klemt, A.I Konopleva, R. Miller and G. Zibold, (2001) in press.

[13] S. Kaminski, T. Richter, M. Walser and G. Lindner, Radiochimica Acta 66/67, 433-436 (1994).

[14] J. Drissner, E. Klemt, Th. Klenk, R. Miller, M. Burger and A. Jakob, Czechoslovak Journal of Physics, 49, 133-139 (1999).

[15] J. T. Smith, A.V. Kudelsky, IN. Ryabov, S.E. Daire, L. Boyer, R.J. Blust, J.A. Fernandez, R.H. Hadderingh and O Voitsekhovitch, J. Environ Radioactivity, submitted for publication (2001).

[16] E. Klemt, A. Konoplev and G. Zibold, ECORAD (2001) 